\title{
Analysis of Ret knockin mice reveals a critical role for IKKs, but not PI 3-K, in neurotrophic factor-induced survival of sympathetic neurons
}

\author{
M Encinas ${ }^{1, \star}$, EJ Rozen ${ }^{1}$, X Dolcet ${ }^{2}$, S Jain ${ }^{3}$, JX Comella ${ }^{1,8}$, J Milbrandt $^{4,5}$ and EM Johnson Jr $^{4,6,7}$
}

We analyzed the survival responses and downstream signaling elicited by GDNF on sympathetic neurons from different Ret knockin mice. Lack of tyrosine 1062, a multidocking site in Ret, completely prevented GDNF-mediated survival. Importantly, lack of tyrosine 981, although abrogating Akt phosphorylation, had no effect on neuronal survival, indicating that the PI 3-K/Akt pathway is not necessary for survival of sympathetic neurons. In contrast, silencing of B-Raf completely prevented not only GDNF-mediated but also NGF-mediated cell survival, independently of MEK-1/2. We identified IKKs as the main effectors of the protective effects of B-Raf. First, B-Raf interacted with and activated IKKs. Second, knockdown of IKKs reversed the protection afforded by a constitutively active form of B-Raf. Third, knockdown of IKKs prevented both NGF- and GDNF-mediated survival. In conclusion, our data delineate a novel survival pathway for sympathetic neurons linking B-Raf to IKKs, independently of both PI 3-K and MEK-1/2 pathways.

Cell Death and Differentiation (2008) 15, 1510-1521; doi:10.1038/cdd.2008.76; published online 23 May 2008

The GDNF family ligands (GFLs) constitute a group of neurotrophic factors (GDNF, NRTN, PSPN and ARTN) that regulate several aspects of the developing nervous system. GDNF and NRTN were identified by virtue of their ability to promote the survival of cultured ventral mesencephalic dopaminergic neurons and sympathetic neurons, respectively. The spectrum of neuronal populations, which survive in response to GFLs has been broadened and now includes sensory, motor, parasympathetic and enteric neurons. ${ }^{1}$

GFLs signal through a common tyrosine kinase receptor (Ret), and one of the four coreceptors known as GFR $\alpha 1-4$. Ret is alternatively spliced to produce at least two variants of identical sequence up to residue 1063 , followed by a unique C-terminal sequence composed of either 9 or 51 amino acids (Ret9 and Ret51) (reviewed in Airaksinen et al. ${ }^{2}$ ).

Ret has five important tyrosines, which serve as docking sites for downstream effectors. Tyr905 binds Grb10 and Grb7, whereas Tyr981 binds Src, Abl and SHB- $\beta$. Phospholipase C- $\gamma$ and Grb2 bind to Tyr1015 and Tyr1096 (which is only present in Ret 51), respectively. Finally, Tyr1062 is a multidocking site, which binds Shc, IRS-1, FRS-2 and Dok4/5/6 (reviewed in Airaksinen and Saarma ${ }^{1}$ ).

After phosphorylation of docking tyrosines and binding to the adequate adaptors, engagement of RTKs leads to the activation of signaling pathways that are ultimately responsible for the biological effects. Among them, the phosphatydilinositol 3-kinase (PI 3-K)/Akt and the extracellular-related kinase 1 and 2 (ERK1/2) pathways have been shown to convey pro-survival signals in many different systems. Since Ret was an orphan receptor for years, most of our knowledge of its signaling properties comes from the analysis of its oncogenic forms. Thus, the relevance of the signaling pathways elicited by ligand-activated endogenous, wild-type Ret, in neuronal function is largely unexplored. On the other hand, the signaling pathways by which NGF, another neurotrophic factor for sympathetic neurons, promotes their survival is controversial, as contradicting reports on the role of the PI 3-K/Akt had been published. ${ }^{3-6}$

We have previously generated knockin mice expressing point mutants of either Ret9 or Ret51 of human origin. These included tyrosine-to-phenylalanine mutations of residues 981 , 1015 and $1062 .{ }^{7}$ In this work, we aim to elucidate the signaling pathways important for the survival of sympathetic neurons using such mutants and GDNF-mediated survival as readout. Our data reveal a critical role for tyrosine 1062, but not tyrosines 981 or 1015, in neuronal survival. Notably, lack of Ret tyrosine 981 impairs Akt phosphorylation but has no effect on cell survival, indicating that the PI 3-K/Akt pathway is not necessary for GDNF-mediated survival of sympathetic neurons. Instead, we find that a novel B-Raf/IKK pathway mediates the pro-survival effects of not only GDNF but importantly also NGF in sympathetic neurons.

\footnotetext{
${ }^{1}$ Cell Signaling and Apoptosis Group, Departament de Medicina Experimental, Lleida 25198, Spain; ${ }^{2}$ Grup de Patologia Oncologica, Departament de Ciències Mèdiques Bàsiques, Institut de Recerca Biomedica de Lleida, Lleida 25198, Spain; ${ }^{3}$ Department of Medicine, Renal Division, St. Louis, MO 63110, USA; ${ }^{4} \mathrm{HOPE}$ center for Neurological Disorders, St. Louis, MO 63110, USA; ${ }^{5}$ Department of Pathology, St. Louis, MO 63110, USA; ${ }^{6}$ Department of Molecular Biology and Pharmacology, St. Louis, MO 63110, USA and ${ }^{7}$ Department of Neurology, Washington University School of Medicine, St. Louis, MO 63110, USA

*Corresponding author: M Encinas, Laboratori d'Investigacio HUAV/UdL, Hospital Universitari Arnau de Vilanova, 1a planta, Rovira Roure, 80, Lleida 25198, Spain; Tel/Fax: + 34 973702213; E-mail: mario.encinas@mex.udl.cat

${ }^{8}$ Current Address: Institut de Neurociències, Universitat Autònoma de Barcelona (UAB), Bellaterra, Spain.

Keywords: neuronal survival; Ret; B-Raf; IKK

Abbreviations: GDNF, glial cell line-derived neurotrophic factor; NGF, nerve growth factor; PI 3-K, phosphatidyl inositol 3-kinase; MEK, MAPK/ERK kinase; ERK extracellular-signal regulated kinase; MAPK, mitogen activated protein kinase; IKK, I kappa B kinase; NF $\kappa$ B, nuclear factor kappa B; RTK, receptor tyrosine kinase Received 30.11.07; revised 17.4.08; accepted 28.4.08; Edited by RA Knight; published online 23.5.08
} 


\section{Results}

Neurons from mice expressing Ret9 or Ret51 display similar responses to GDNF. As mentioned above, two Ret splicing isoforms that differ at the carboxy terminus have been identified (Ret9 and Ret51). We wanted to analyze whether such differences affected Ret downstream signaling or bioactivity in sympathetic neurons. We first verified that neurons expressed the expected Ret isoforms by immunoprecipitating Ret from cultured sympathetic neurons from mice expressing either wild-type Ret9 or Ret51 (Figure 1a). We next checked the activation of the PI 3-K/ Akt and Ras/MAPK pathways. Lysates from neurons stimulated with GDNF for $10 \mathrm{~min}$ were probed with phosphoantibodies specific for phosphorylated Ser473 Akt and dually phosphorylated ERK1/2. No differences between Ret $^{R E T 9}$ or Ret ${ }^{R E T 51}$ knockin mice and their wild-type littermates were detected, despite the observation that mutant mice appeared to express slightly less Ret than wild-type animals (Figure 1b). Finally, we analyzed the survival response prompted by GDNF on neurons from $\operatorname{Ret}^{R E T 9}$ and Ret ${ }^{R E T 51}$ mice. As shown in Figure 1c, GDNF promoted the survival of $80-90 \%$ of neurons from both Ret $^{R E T 9}$ and Ret ${ }^{R E T 51}$ knockin mice, a response, which was similar to that of their wild-type littermates. This survival response was also comparable to NGF-dependent survival of both mutant and wild-type neurons. In summary, despite the differences between Ret9 and Ret51, the two splicing isoforms appear to elicit similar biological responses to GDNF in sympathetic neurons.

Akt and ERK1/2 activation are differentially affected by the mutation of tyrosines 981,1015 or 1062 in the context of Ret9. To ascertain the role of Ret tyrosines 981, 1015 and 1062 in GDNF-mediated downstream signaling in sympathetic neurons, we checked the activation of both Akt and ERK1/2 after acute $(10 \mathrm{~min})$ stimulation with GDNF in

a

\begin{tabular}{|c|c|c|c|c|}
\hline \multirow[b]{3}{*}{ IB:Total Ret } & \multicolumn{2}{|c|}{ IP:Ret9 } & \multicolumn{2}{|c|}{ IP:Ret51 } \\
\hline & Ret9 & WT & Ret9 & WT \\
\hline & 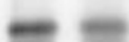 & -5 & & $-1=$ \\
\hline & Ret51 & WT & Ret51 & WT \\
\hline IB:Total Ret & $x^{2}+x^{2}$ & $x=$ & 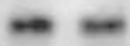 & $=0$ \\
\hline
\end{tabular}
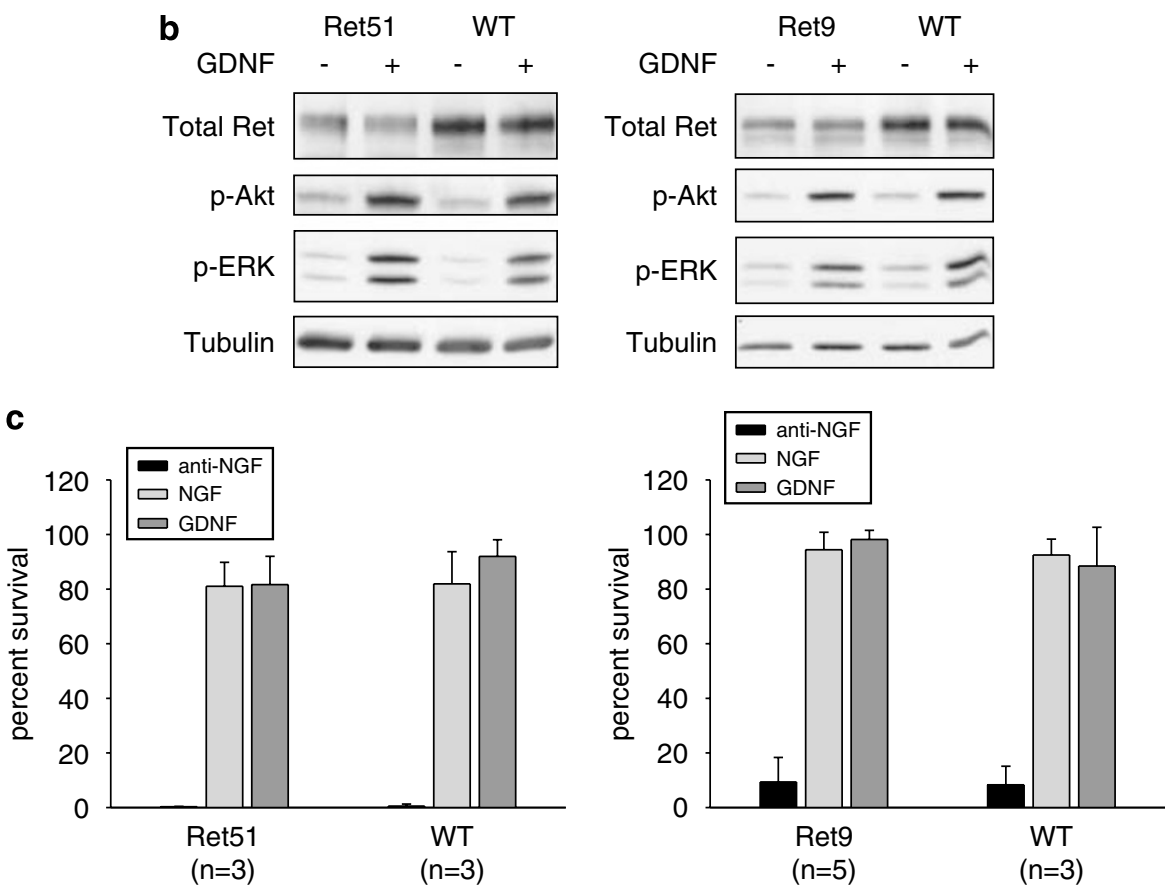

Figure 1 Neurons from knockin mice expressing only Ret9 or Ret51 display similar responses to GDNF. (a) Ret knockin mice express the expected splice isoforms. Lysates from sympathetic neurons from knockin mice expressing human, wild-type Ret9 or Ret51 were immunoprecipitated with the indicated isoform-specific antibodies and probed with a Ret antibody raised against the extracellular domain of the receptor (total Ret). Note the difference in electrophoretic mobility between Ret9 and Ret51. (b) Signaling from neurons expressing only Ret9 or Ret51 is indistinguishable from that of wild-type neurons. Cells were stimulated for 10 min with GDNF and lysates were probed with phosphospecific antibodies to phosphor-Ser473 Akt and dually phosphorylated ERK1/2. (c) GDNF fully rescues sympathetic neurons from both Ret ${ }^{R E T 9}$ and Ret ${ }^{R E T 51}$ knockin mice. Neurons from each genotype were cultured in NGF for 5 days and then incubated with media containing a blocking anti-NGF antibody, NGF or GDNF. Neuronal survival was scored $48 \mathrm{~h}$ later as described in Materials and Methods section. The number in parenthesis depicts the number of animals analyzed 
lysates from mice lacking the above tyrosines, and compared mutant mice with their wild-type littermates. In the context of Ret9, lack of tyrosine 981 caused an almost complete abrogation of Akt phosphorylation together with a remarkable but less drastic reduction in ERK1/2 activation. Mutation of tyrosine 1015, on the other hand, decreased both Akt and ERK1/2 phosphorylation to approximately a half, whereas sympathetic neurons from Ret ${ }^{R E T 9(Y 1062 F)}$ mice showed no activation of either pathway above the baseline (Figure 2). Essentially, the same results were obtained when GDNF stimulation was performed for $24 \mathrm{~h}$ (Supplementary Figure 1). Surprisingly, none of the three mutations caused a significant change in the pattern of phosphorylation of either Akt or ERK1/2 in the context of Ret51 (data not shown and ${ }^{7}$ ).

These data, together with the observation that mice expressing either Ret51(Y1062F) or truncated Ret51 lacking
Tyr1096 develop normal kidneys, whereas Y1062F mutation introduced in Ret9 results in kidney agenesis, ${ }^{7}$ suggest that Tyr1096 plays a redundant role in Ret signaling. To characterize the effects of mutations of Ret tyrosines 981, 1015 and 1062 without the confounding effects of redundant signaling by the carboxy terminus of Ret51, we performed further studies only in the context of the Ret9 isoform.

Mutation of tyrosine 1062, but not 981 or 1015 abrogates GDNF-mediated survival. Having shown that mutation of tyrosines 981, 1015 and 1062 in Ret9 decreased downstream signaling, we sought to analyze the effects of their absence on GDNF-mediated neuronal survival. Surprisingly, neurons from $\operatorname{Ret}^{R E T 9(Y 981 F)}$ mice did not show any reduction on GDNF-mediated survival (Figure 3, left column and Supplementary Figure 1), despite causing almost no phosphorylation of Akt. Neurons survived to levels a

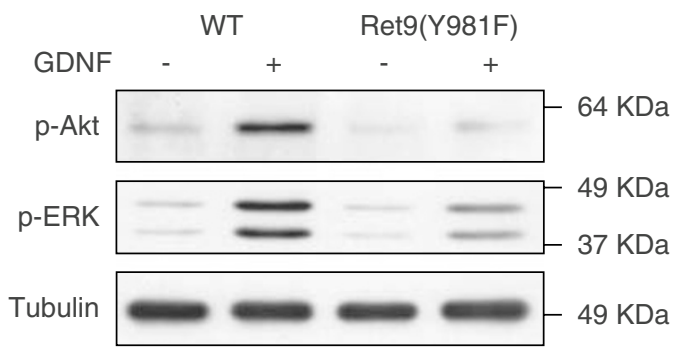

b

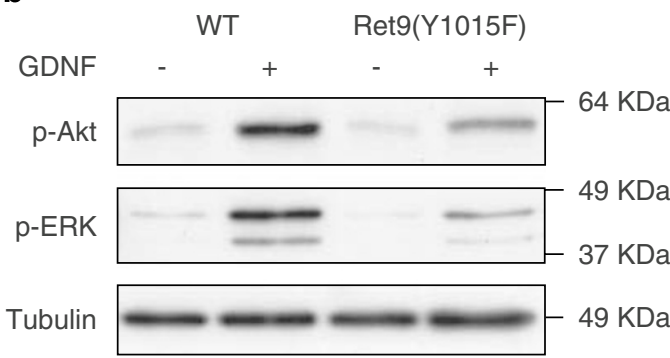

C

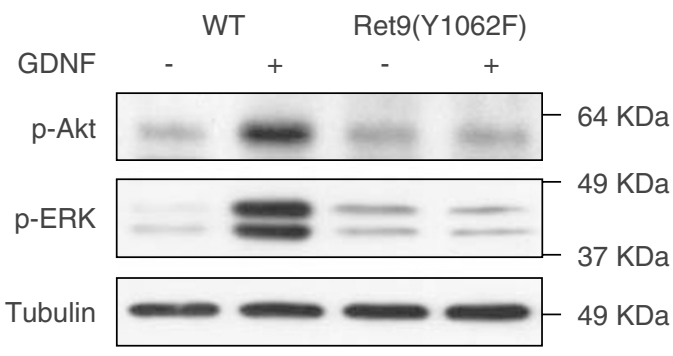

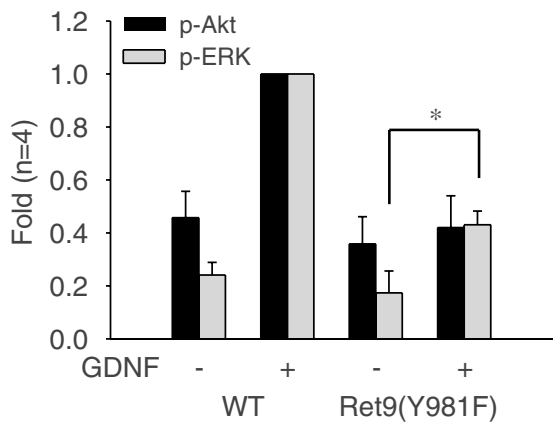
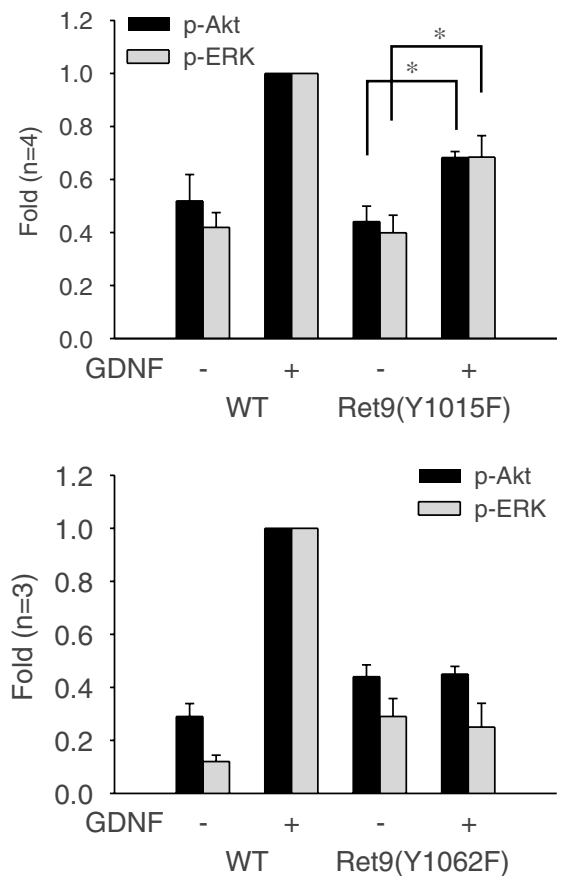

Figure 2 Mutation of Ret tyrosines 981, 1015 or 1062 differentially affects GDNF-mediated downstream signaling. Representative immunoblots of phospho-Ser473 Akt and dually phosphorylated ERK1/2 from sympathetic neurons from $\operatorname{Ret}^{R E T 9(Y 981 F)}(\mathbf{a})$, $\operatorname{Ret}^{R E T 9(Y 1015 F)}$ (b) or Ret ${ }^{R E T 9(Y 1062 F)}$ mice (c). For comparison, wild-type littermates are shown. Lack of tyrosine 981 caused an almost complete abrogation of Akt phosphorylation and reduced ERK phosphorylation to a lesser extent. In Ret ${ }^{R E T 9(Y 1015 F)}$ animals, both Akt and ERK phosphorylation was decreased approximately 50\%, whereas mutation of tyrosine 1062 blocked both Akt and ERK phosphorylation to basal levels. Right panels show densitometric analysis of the indicated number of independent experiments. Data are expressed as mean \pm S.E.M. of fold induction. Asterisks depict $P<0.05$ by two-tailed $t$-test 

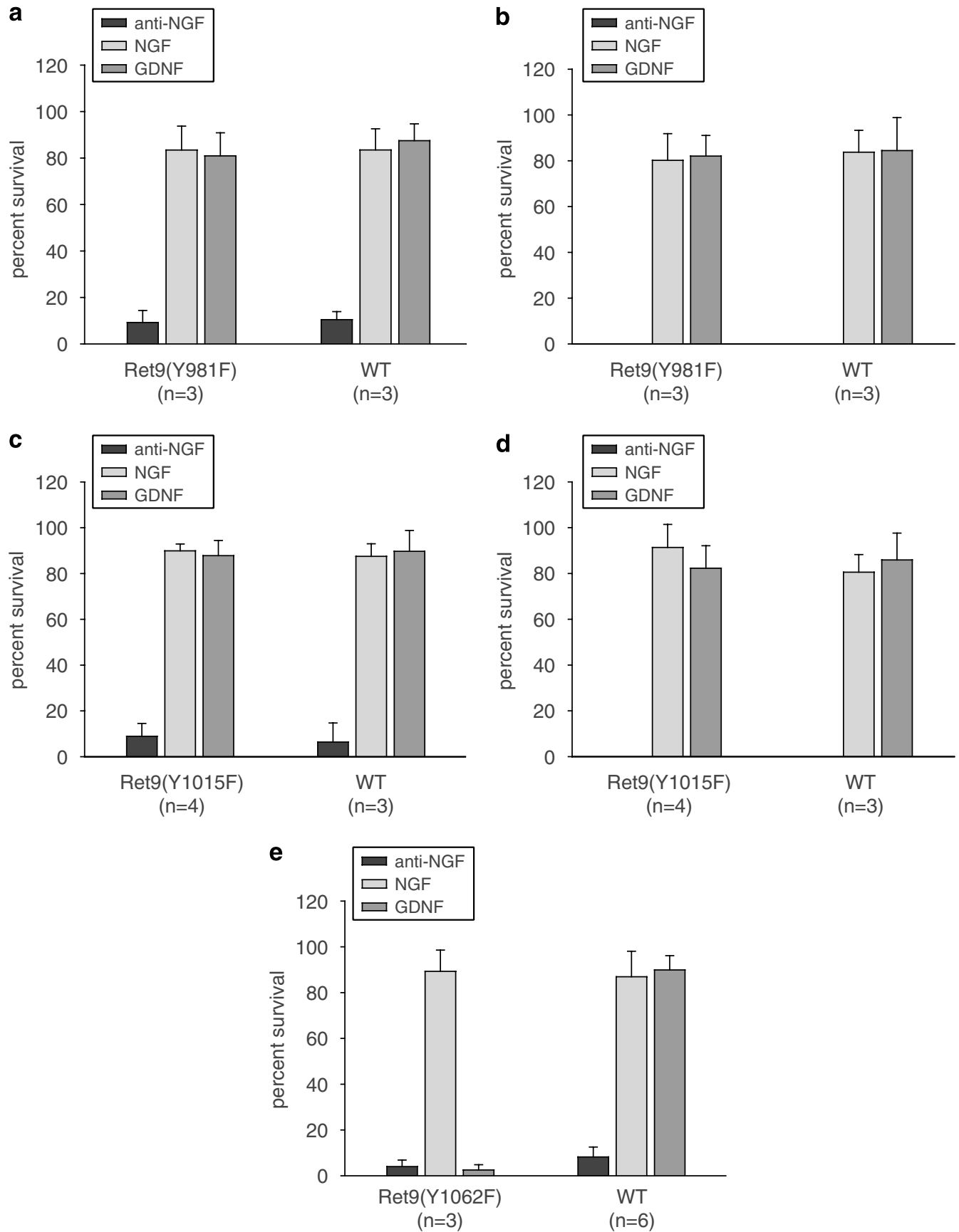

Figure 3 Only neurons from Ret ${ }^{R E T 9(Y 1062 F)}$ mice fail to survive in the presence of GDNF. Quantification of the survival response to GDNF of sympathetic neurons from mice lacking tyrosine 981 (a and b), tyrosine 1015 (c and d) or tyrosine 1062 (e). The graphs on the left (a, $\mathbf{c}$ and $\mathbf{e}$ ) depict survival $48 \mathrm{~h}$ after switching cells to GDNF, whereas the right panels ( $\mathbf{b}$ and $\mathbf{d}$ ) show the same cultures 1 week after switch. NGF-supported neurons were used as a control. The survival was compared to those of wild-type littermates. Number in parenthesis depicts the number of animals of each genotype analyzed

similar to those achieved by their wild-type littermates or by neurons from $\operatorname{Ret}^{R E T 9}$ mice. The survival response was similar to that elicited by NGF, and lasted at least up to 7 days, the last time point analyzed (Figure 3, right column and Supplementary Figure 2). Neurons from Ret ${ }^{R E T 9(Y 1015 F)}$ mice showed a similar response, that is, full rescue by GDNF (Figure(3 and Supplementary Figure 2), whereas mutation of tyrosine 1062 completely prevented GDNF-mediated survival. Neurons expressing this mutation responded normally to NGF, demonstrating that the effect was specific for GDNF (Figure 3). Thus, although mutation of tyrosines 981 and 1015 diminished the activation of both Akt and ERK1/2, only mutation of tyrosine 1062 prevented GDNFmediated survival of sympathetic neurons.

Neither the PI 3-K/Akt nor the MEK/ERK pathways are necessary for GDNF-mediated survival. Since the 
reduction of Akt phosphorylation in neurons from $\operatorname{Ret}^{\text {RET9(Y981F) }}$ animals did not correlate with a decrease in cell survival, we directly tested the role of the PI 3-K pathway on GDNF-mediated survival of sympathetic neurons. Addition of increasing doses of LY294002, a selective inhibitor of PI 3-K, did not kill a significant number of wildtype neurons when compared to vehicle-treated cells. The same doses inhibited Akt phosphorylation to basal levels suggesting a complete blockade of GDNF-mediated PI 3-K signaling (Figure $4 \mathrm{a}$ ).

PDK1 is a 'master' kinase linking PI $3-\mathrm{K}$ activation to its more relevant downstream effectors, namely Akt and other members of the AGC family of kinases (reviewed in Mora et $a l^{8}{ }^{8}$. Consistent with the results obtained with LY294002, lentiviral delivery of shRNA against PDK1 had no effect on cellular survival, further confirming that the PI 3-K/Akt
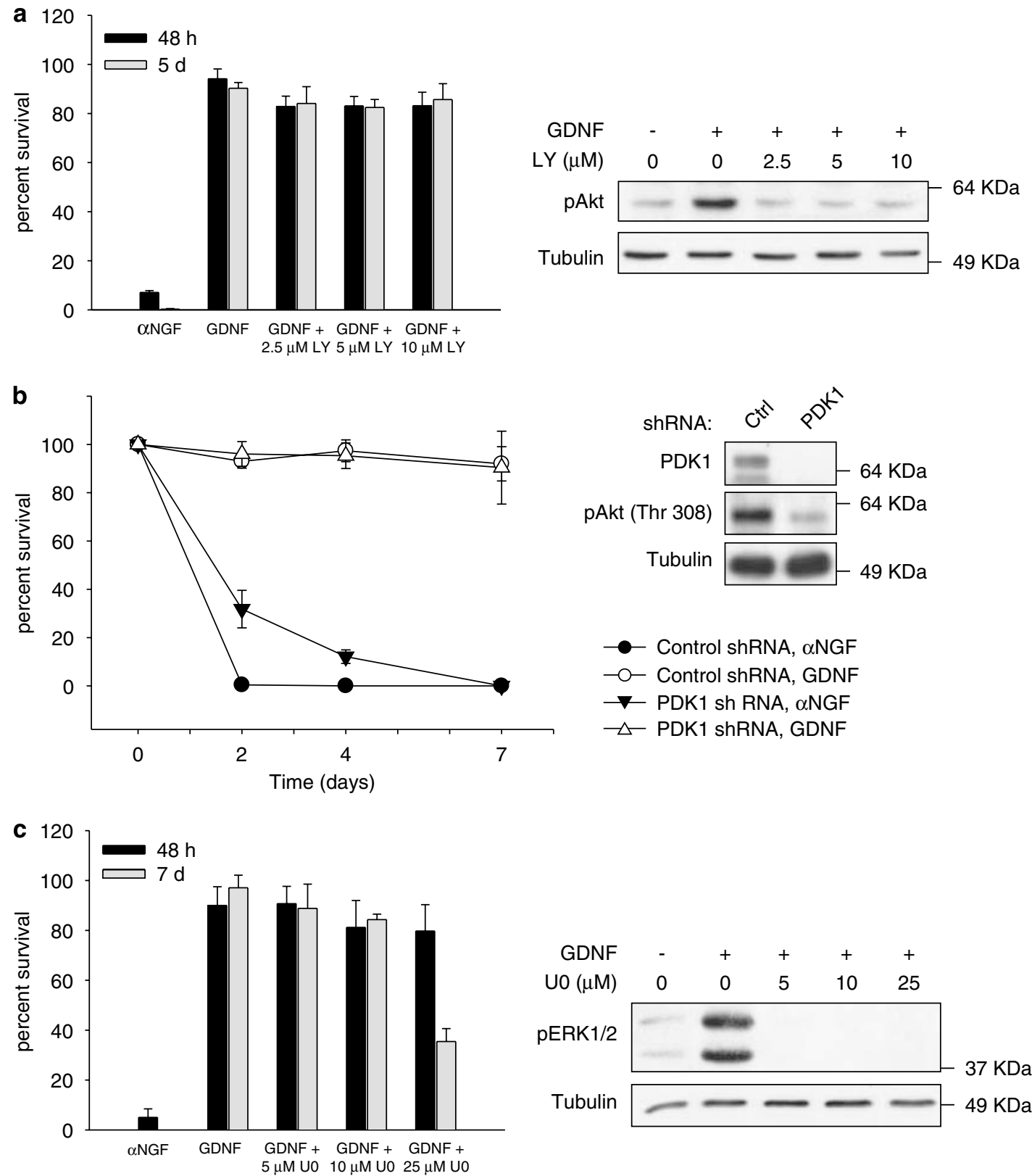

Figure 4 Neither PI 3-K/Akt nor ERK1/2 is necessary for GDNF-mediated survival. (a) Sympathetic neurons from wild-type mice were cultured for 5 days in NGF and then switched to GDNF with or without the indicated doses of the PI 3-K inhibitor LY294002. Neuronal survival was assessed $48 \mathrm{~h}$ and 5 days after switch (left panel). In the right panel, lysates from neurons stimulated with GDNF in the presence of the indicated doses of LY294002 were probed with an antiphospho-Ser473 Akt. (b). Neurons were infected with lentiviruses expressing short-hairpin RNA (shRNA) against PDK1 as specified in Materials and Methods. Neurons were kept in NGF for 6 days and then switched to the indicated treatments. Neuronal survival was scored at the indicated time points after switch (left panel). In the right panel, the efficiency of the knockdown as well as the phosphorylation of Akt was assessed by western blot. (c) Cells were treated as in panel a but with the indicated doses of the MEK inhibitor U0126. Survival was assessed after $48 \mathrm{~h}$ and 7 days after treatment (left panel). Right panel, lysates were probed with an antibody to dually phosphorylated ERK1/2 to check the efficacy of the inhibitor 
pathway is not necessary for GDNF-mediated survival of sympathetic neurons (Figure 4b).

Another candidate group of signaling intermediates that could be important for GDNF-mediated neuronal survival are the MAPK family members ERK $1 / 2$. We used U0126, a highly selective inhibitor of MEK1/2, the kinases upstream of ERK1/ 2. U0126 did not prevent the pro-survival effect of GDNF, at doses that effectively blocked phosphorylation of ERK1/2 (Figure 4c). Very high doses of U0126 $(25 \mu \mathrm{M})$ reduced cell survival after 1 week of treatment, suggesting a toxic effect of the drug. PD98059, the second MEK inhibitor used, also failed to block the survival of these neurons in the presence of GDNF (data not shown). Therefore, since two structurally unrelated MEK inhibitors did not prevent cell survival, it is unlikely that any of these kinases participate in the prosurvival effects of GDNF. In experiments using both $\mathrm{PI} 3-\mathrm{K}$ and MEK1/2 inhibitors, we replaced the medium every $24 \mathrm{~h}$ to ensure sustained blockade of the pathways. As shown in Supplementary Figure 1, both inhibitors efficiently blocked activation of their respective targets after $24 \mathrm{~h}$ of stimulation.

The PI 3-K/Akt pathway supports cell growth. As sympathetic neurons mature in the presence of NGF, they progressively increase their size and become independent of NGF for survival. Thus, in mature neurons, NGF is required to stimulate the anabolic metabolism of the cell but not its survival, ${ }^{9}$ indicating that cell growth and cell survival are regulated independently in these neurons. Silencing of PDK1, although not causing cell death, resulted in a marked reduction in the soma diameter of these neurons, indicating that $\mathrm{PI} 3-\mathrm{K}$ signaling stimulates cell growth (Figure $5 \mathrm{a}$ and $\mathrm{b}$ ). Consistent with this observation, neurons from Ret ${ }^{R E T 9(Y 981 F)}$ animals increased their size over time in the presence of GDNF at a much slower rate than those from either $\operatorname{Ret}^{R E T 9}$ or $\operatorname{Ret}^{R E T 9(Y 1015 F)}$ mice (Figure $5 \mathrm{c}$ but see also Supplementary Figure 2). Therefore, as is the case for $\mathrm{NGF}^{6}{ }^{6}$ it appears that GDNF relies on the activation of the $\mathrm{PI} 3-\mathrm{K} / \mathrm{Akt}$ pathway to stimulate cell growth of sympathetic neurons.

Neurotrophic factor-induced neuronal survival of sympathetic neurons is mediated by B-Raf. The lack of phosphorylation of ERK1/2 in neurons from Ret ${ }^{R E T(Y 1062 F)}$ mice correlated with the failure of GDNF to support survival of these sympathetic neurons, whereas in neurons from mice carrying either Ret Y981F or Y1015F this pathway, while diminished, was still active. Although experiments with U0126 ruled out a role of ERK $1 / 2$ in neuronal survival, it was still possible that apical elements of the pathway such as Ras or Raf could be involved in the pro-survival effects of GDNF, in a MEK-independent fashion. Lentiviral delivery of shRNAs against A-Raf, B-Raf and C-Raf effectively blocked the expression of each family member (Figure 6a-c). However, the protective effects of GDNF in cultured sympathetic neurons were only reversed by decreasing B-Raf levels. Importantly, knockdown of B-Raf killed sympathetic neurons also in the presence of NGF (Figure 6d). Finally, overexpression of a constitutively active form of B-Raf (V600E) was able to rescue trophic factor-deprived sympathetic neurons from death (Figure 7a). a
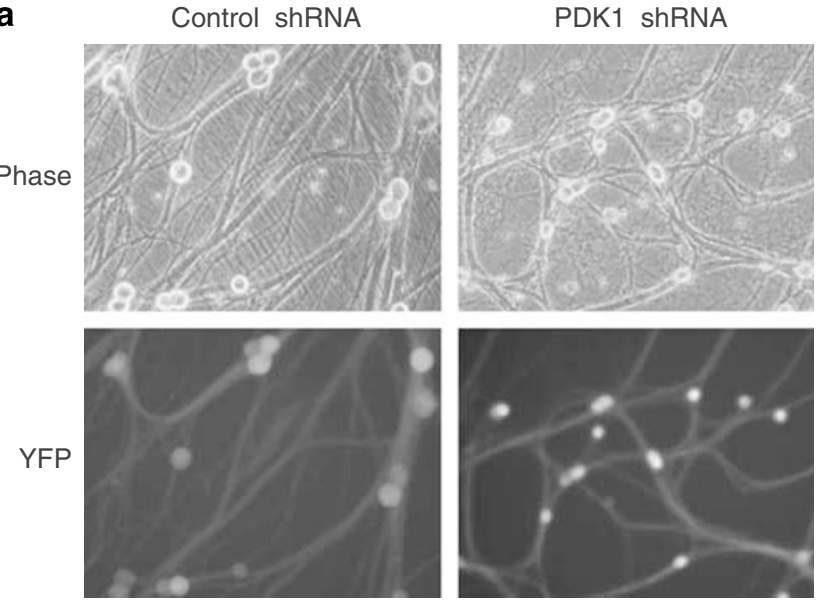

b

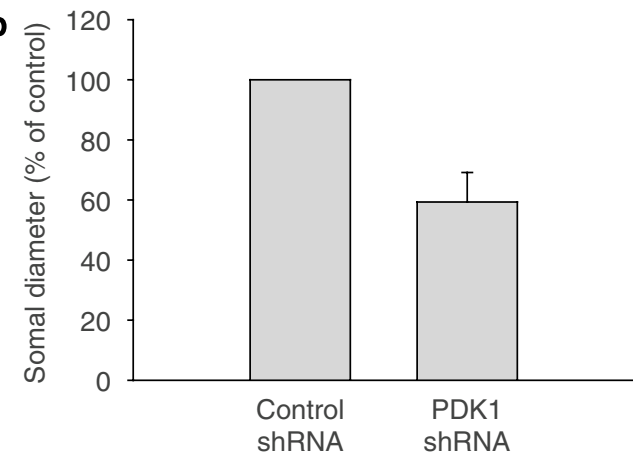

C

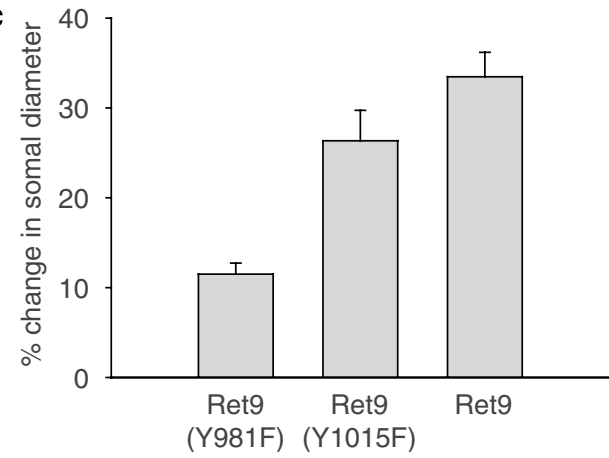

Figure 5 (a and $\mathbf{b})$ Knockdown of PDK1 reduces cell growth. Wild-type mouse sympathetic neurons were infected with lentiviruses expressing shRNA to PDK1 as in Figure 6. Pictures were taken after 14 days in culture using a fluorescence microscope to show both the morphology and the degree of infection by visualizing expression of YFP. In panel $b$, the soma diameter was measured as described in Material and Methods. (c) Loss of Ret tyrosine 981 reduces cell growth. Sympathetic neurons from knockin mice expressing either Ret9, Ret9(Y981F) and Ret9(Y1015F) were kept in NGF for 5 days, then switched to GDNF and maintained for 7 additional days. Soma diameter was measured at the time of GDNF addition and 7 days after, and the percentage of increase in the soma size over this period of time was calculated

This observation is consistent with a critical role of B-Raf in neurotrophic factor-mediated survival of sympathetic neurons.

IKKs are downstream effectors of B-Raf in sympathetic neurons. Currently, it is unclear by which mechanism Raf kinases promote their biological effects independently of 

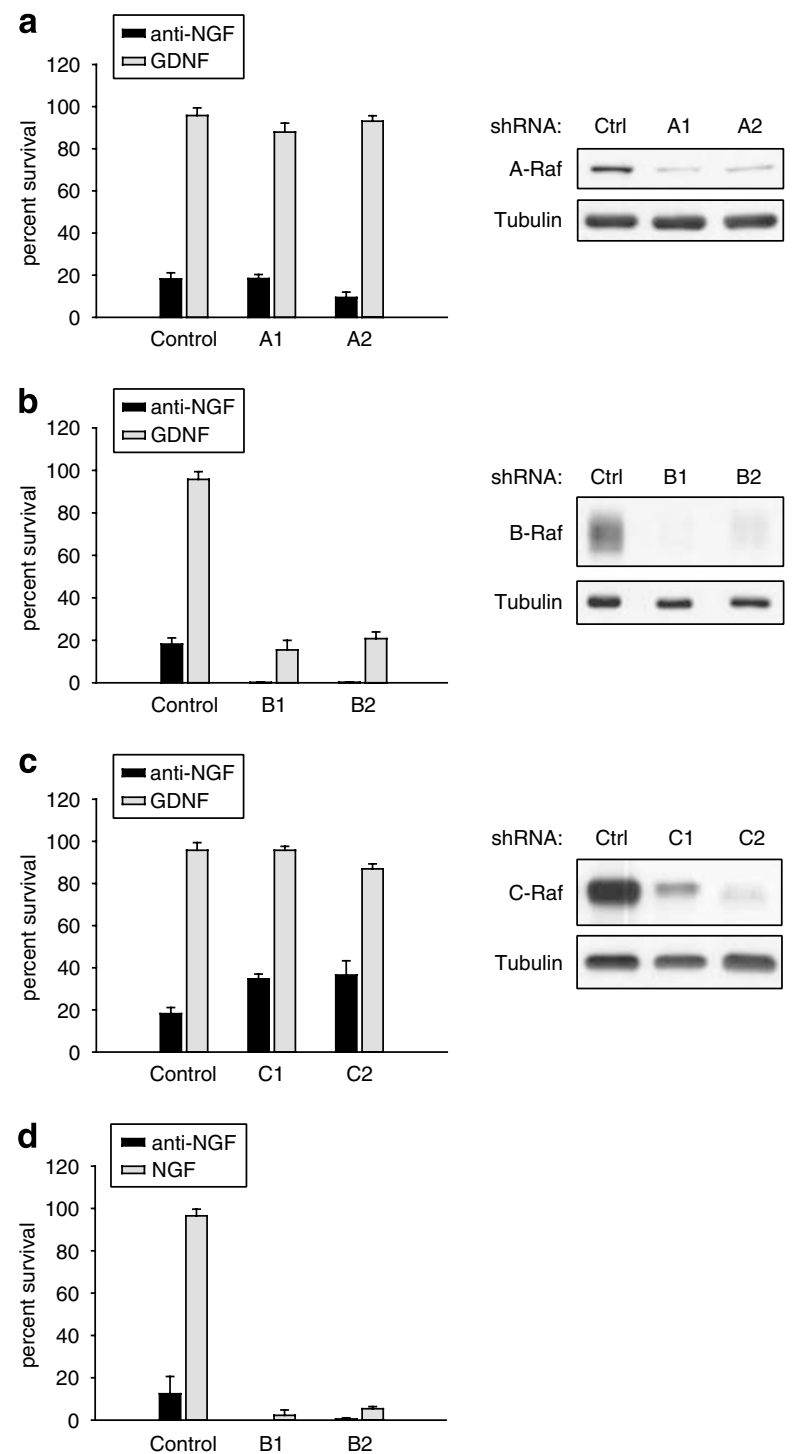

Figure 6 Knockdown of B-Raf, but not A-Raf or C-Raf, prevents GDNF- and NGF-mediated survival of wild-type mouse sympathetic neurons. ( $\mathbf{a}, \mathbf{b}$ and $\mathbf{c}$ ) Left panels: neurons were infected with lentiviruses expressing shRNAs to A-Raf (A1 and A2), B-Raf (B1 and B2) and C-Raf (C1 and C2) 1 day after plating as described in Materials and Methods. Neurons were cultured in NGF for 5 days and then switched to GDNF. Survival was assessed after $48 \mathrm{~h}$ in the presence of GDNF. Right panels: the efficacy of the knockdown was assessed by immunoblot using isoform-specific Raf antibodies. In the case of B-Raf, cells were saved by the addition of the pan-caspase-inhibitor BAF 2 days before lysis. (d) Same as in panel $b$, but cells were treated with NGF instead of GDNF

MEK-1/2. Several putative Raf targets such as MTS-2, Rok- $\alpha$, Bad and the NF- $\kappa$ B pathway had been proposed (reviewed in Wellbrock et al. ${ }^{10}$ and Galabova-Kovacs et al. ${ }^{11}$ ). We chose to test the latter, because the NF- $\kappa \mathrm{B}$ pathway has been reported to block apoptosis in sympathetic and sensory neurons. ${ }^{12,13}$ In the so-called canonical NF- $\kappa$ B pathway, activated IKK complex formed by two catalytic subunits (IKK $\alpha$ and $\operatorname{IKK} \beta)$ and a regulatory subunit $(\mathrm{IKK} \gamma)$ phosphorylates the inhibitors of NF- $\kappa \mathrm{B}\left(l_{\kappa} \mathrm{B}\right)$, which become degraded by the proteasome. Degradation of $I \kappa B$ frees cytoplasmic NF- $\kappa$ B

dimers, which translocate to the nucleus to activate transcription of target genes. As shown in Figure 7b, simultaneous silencing of both $\mathrm{IKK} \alpha$ and $\mathrm{IKK} \beta$, but not the inhibition of $\mathrm{PI} 3-\mathrm{K}$ or MEK-1/2, reversed the protection afforded by V600E B-Raf, suggesting that IKKs are downstream effectors of B-Raf. To further confirm this notion, we examined whether NGF or GDNF were able to activate IKKs in a B-Raf-dependent manner. Both neurotrophic factors induced phosphorylation of IKK $\alpha$ and IKK $\beta$ in their activation loop (Figure 7c). Silencing of B-Raf prevented phosphorylation of IKKs, indicating that the activation of IKKs by NGF or GDNF requires B-Raf (Figure 7c). Finally, we tested whether B-Raf and IKKs form a complex in sympathetic neurons. As shown in Figure $7 d$, endogenous B-Raf coimmunoprecipitated with endogenous $\mathrm{IKK} \alpha$ or $\mathrm{IKK} \beta$ independently of trophic factor stimulation, indicating that IKKs and B-Raf are constitutively associated in these neurons. Interestingly, our preliminary results indicate that such binding is retained in organs from newborn mice such as brain, heart or skin (data not shown), suggesting that the B-Raf//KK pathway could operate in other cell types outside the nervous system. Taken together, these results place IKKs as downstream targets mediating the prosurvival effects of B-Raf.

IKKs are necessary for NGF- and GDNF-mediated survival of sympathetic neurons. Having shown that silencing of IKKs prevents the survival effects of $\mathrm{V} 600 \mathrm{E}$ B-Raf, we next wanted to ascertain whether IKKs are necessary for neurotrophic factor-induced survival of sympathetic neurons. Silencing of IKKs in conjunction or individually (Figure $8 \mathrm{a}$ and $\mathrm{b}$, respectively) killed sympathetic neurons maintained in the presence of either NGF or GDNF, indicating that both $\mathrm{IKK} \alpha$ and $\mathrm{IKK} \beta$ are necessary for neuronal survival triggered by NGF or GDNF. Such phenomenon was not restricted to mouse sympathetic neurons, as rat sympathetic neurons or mouse trigeminal neurons also died when either IKKs or B-Raf were silenced (Supplementary Figure 3 ). Silencing of IKK $\beta$ caused an increase in BimEL and PUMA levels in the presence of NGF, to levels comparable to those reached after NGF deprivation (Figure 7c). On the other hand, knockdown of Bax suppressed cell death caused by both NGF deprivation and lack of IKK $\beta$ (Figure 7d). These results, therefore, suggest that cell death caused by loss of IKK signaling mimics trophic factor withdrawal-induced cell death. ${ }^{14}$ Finally, we checked the status of IKKs in sympathetic neurons from Ret ${ }^{\text {RET(Y981F) }}$ and $\operatorname{Ret}^{R E T(Y 1062 F)}$ mice. As expected, mutation of tyrosine 1062 completely prevented activation of IKKs, whereas lack of tyrosine 981 had little or no effect (Figure 8e).

\section{Discussion}

Regulation of the PI 3-K/Akt and the ERK1/2 pathways by Ret tyrosines. Absence of tyrosine 1062 results in blockade of phosphorylation of both Akt and ERK $1 / 2$ to baseline. Importantly, B-Raf is the major MEK kinase in sympathetic neurons (Supplementary Figure 2), indicating that Ret9(Y1062F) is unable to activate B-Raf upon GDNF 

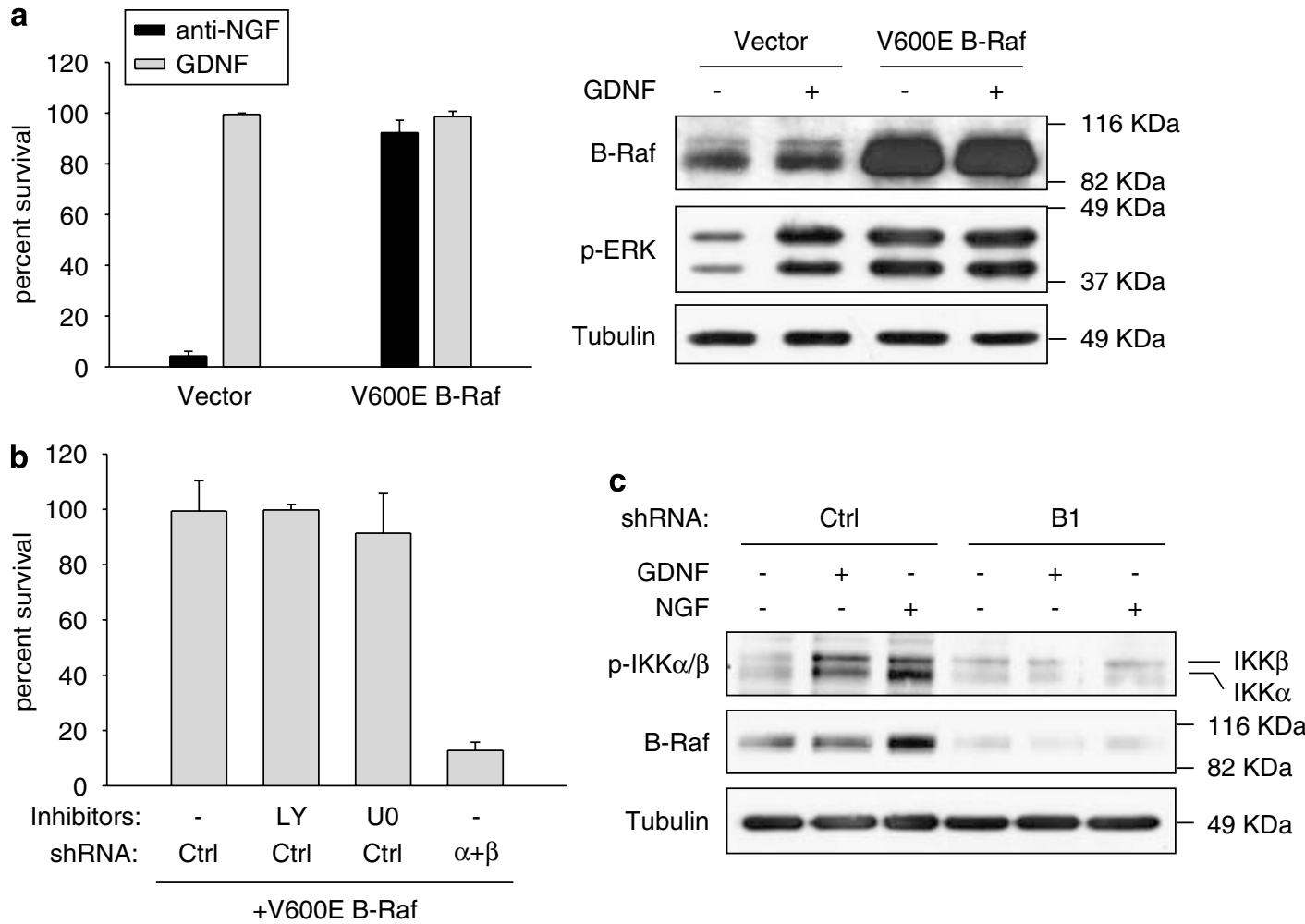

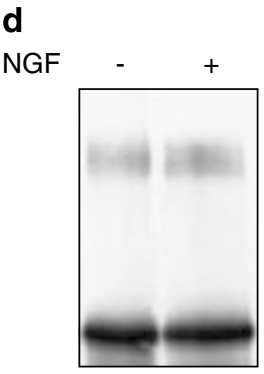

IP: IKK $\beta$

IB: B-Raf

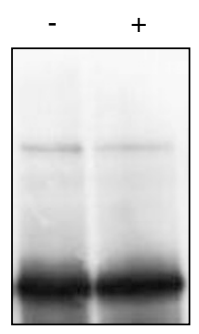

IP: IKK $\beta$

IB: IKKo

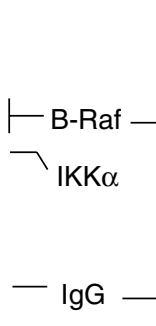

-

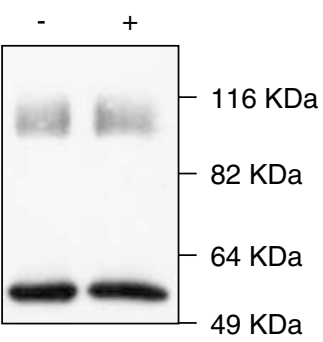

IB: B-Raf

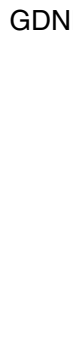

Figure $7 \quad \mathrm{IKK} \alpha$ and IKK $\beta$ are downstream effectors of B-Raf. (a) A constitutively active form of B-Raf (V600E) rescues trophic factor-deprived neurons. Left, cells were infected with a lentiviral construct coding for human V600E B-Raf or empty vector. Four days later, cells were switched to media containing a blocking anti-NGF antibody or GDNF. Survival was assessed after $48 \mathrm{~h}$ in the presence of GDNF. Right, V600E B-Raf mutant is constitutively active. Cells infected with V600E B-Raf or empty vector were stimulated with for $10 \mathrm{~min}$ with GDNF and lysates probed with antibodies to B-Raf and dually phosphorylated ERK1/2. (b) Silencing of IKKs, but not the inhibition of PI 3-K or MEK, reverses the protection afforded by V600E B-Raf. Cells were sequentially infected, as described in Materials and Methods, with V600E B-Raf, and either with control shRNAs or with a mixture of shRNAs to IKK $\alpha$ and IKK $\beta(\alpha+\beta)$. Three days later cells were deprived and kept in the presence of the indicated inhibitors (10 $\mu$ M each) for two additional days, after which survival was evaluated. (c) B-Raf acts upstream of IKKs. Cells were infected with control shRNAs or a shRNA to B-Raf ('B1'). Four days after infection, cells were deprived overnight in the presence of $50 \mu \mathrm{M} \mathrm{BAF}$. Cells were stimulated for $10 \mathrm{~min}$ with the indicated factors and lysates probed against phospho-IKKs, BRaf or tubulin. (d) Endogenous IKKs and B-Raf form a complex in sympathetic neurons. Neurons were kept in NGF for five days, deprived overnight and stimulated for 10 min with medium alone or containing the indicated factor. IKK $\beta$ or IKK $\alpha$ were immunoprecipitated and lysates were immunoblotted (IB) with the indicated antibodies. In the right panel, $5 \%$ of the input lysate was resolved in parallel to IKK $\beta$ immunoprecipitates

stimulation. Ret activates both the PI 3-K/Akt pathway and the Ras/ERK pathway through the recruitment of the adaptor protein Grb2 to phosphorylated Shc and/or FRS-2. ${ }^{15,16}$ Binding of Grb2 to Gab1/2 activates the PI 3-K/Akt pathway, whereas binding of Grb2 to Sos activates ERK1/2 through Ras-Raf-MEK. As mentioned earlier, both Shc and FRS-2 bind to phosphotyrosine 1062 and therefore, its absence would impair the phosphorylation of such adaptors and its subsequent binding to Grb2. How Tyr981 regulates these pathways in the case of Ret signaling is unclear but many possibilities exist, such as phosphorylation of Dok6 through an Src family kinase, ${ }^{17,18}$ tyrosine phosphorylation of Akt by $\mathrm{Src}^{19}$ or inhibition of PTEN activity by an Src family kinase. $^{20}$ In any case, the mechanisms by which these tyrosines regulate downstream signaling need to be further explored. 

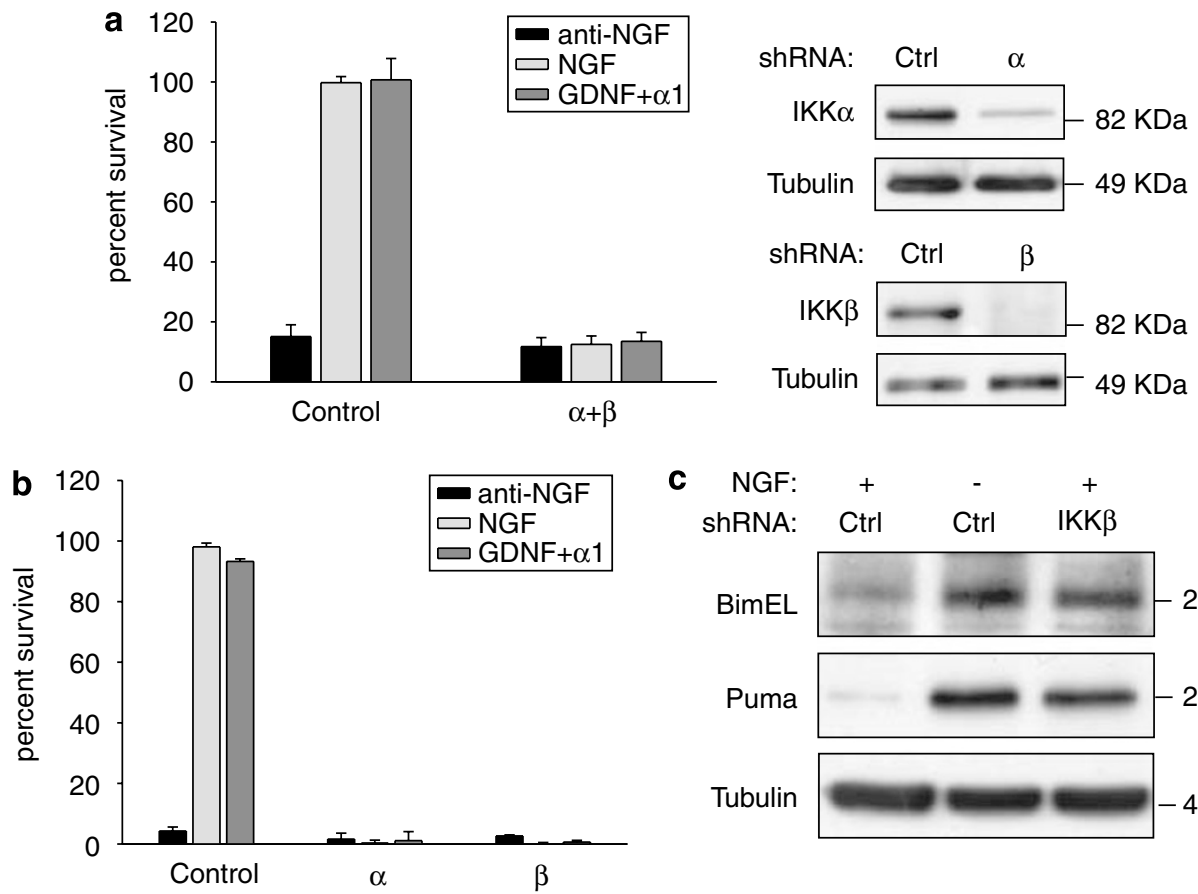
C NGF: $\quad+\quad-\quad+$ shRNA: Ctrl Ctrl IKK $\beta$

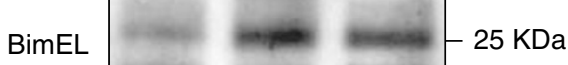

Puma

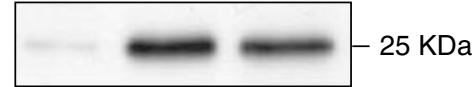

Tubulin
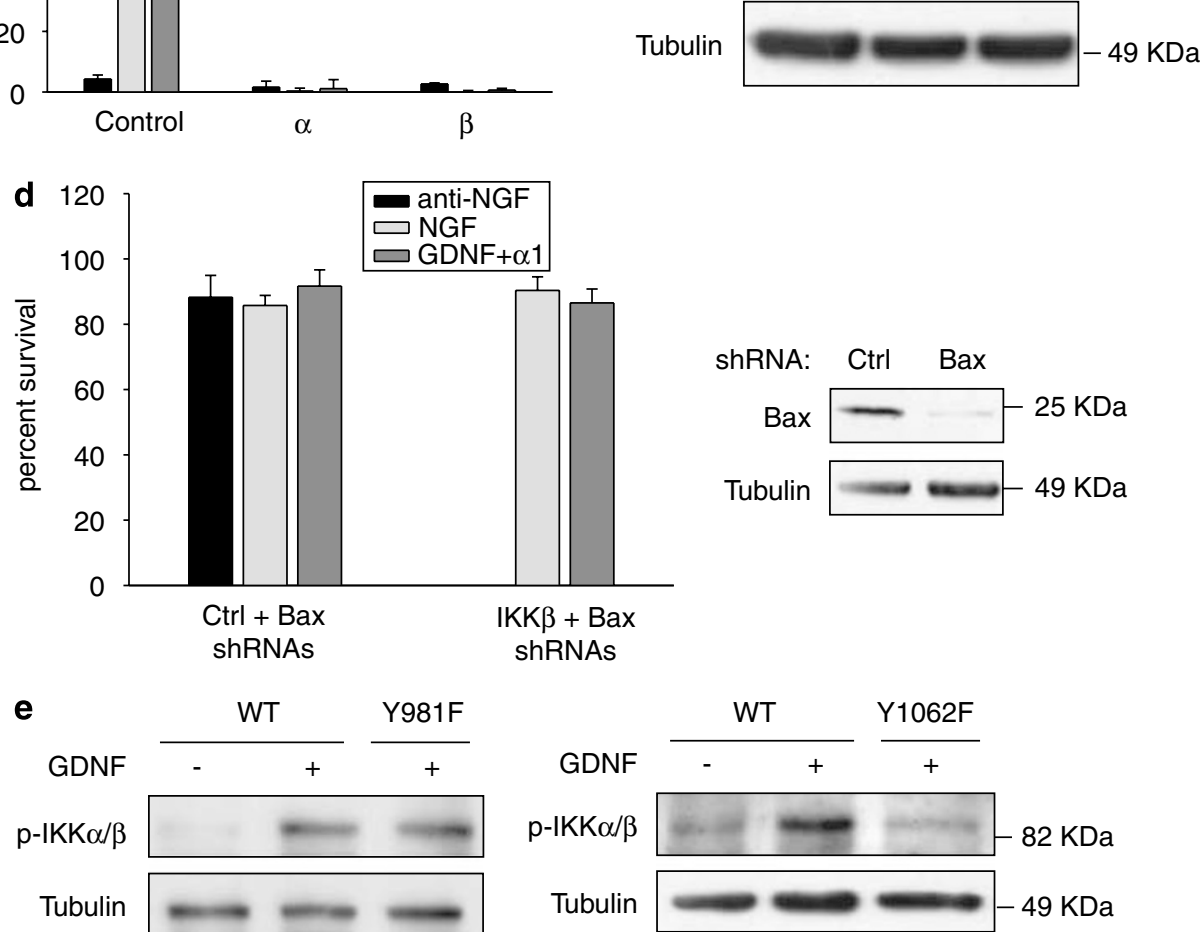

Figure 8 IKKs are necessary for NGF- and GDNF-mediated survival of sympathetic neurons. (a and $\mathbf{b})$ Neurons were infected with shRNAs to IKKs in combination $(\alpha+\beta)$ or alone $(\alpha$ or $\beta) 2$ days after plating. After 3 additional days in the presence of NGF, cells were switched to the indicated factors and survival was evaluated $48 \mathrm{~h}$ later. The right panel shows efficacy of the knockdown. (c) Silencing of IKKs induces BimEL and PUMA expression. On the second day after plating, Cells were infected with control shRNAs or with an shRNA to IKK $\beta$ and kept on NGF for 3 additional days. Cells were then deprived or kept in NGF for $24 \mathrm{~h}$ more as depicted, and BimEL and PUMA expression was assessed by western blot. (d) Silencing of Bax rescues cells from the knockdown of IKK $\beta$. Cells were infected with shRNAs to Bax, and subsequently infected with control or with shRNAs to IKK $\beta$ as detailed in Materials and Methods. Cells were maintained in NGF for 3 additional days, and switched to media containing the indicated factors. Cell survival was assessed $48 \mathrm{~h}$ later. Right panels shows efficacy of the knockdown. (e) Loss of tyrosine 1062, but not tyrosine 981, blocks GDNF-mediated phosphorylation of $\mid \mathrm{KK} \alpha / \beta$. Sympathetic neurons form the indicated genotypes were cultured in the presence of NGF for 5 days, deprived overnight and stimulated for 10 min with GDNF. Blots were probed with antibodies to phospho-IKKs. Note that owing to a higher acrylamide percentage, IKK $\alpha$ and IKK $\beta$ were not resolved as in Figure 7c

The role of PI 3-K/Akt in neuronal survival. Our data do not support a significant role of the PI 3-K/Akt pathway in GDNF-mediated neuronal survival of sympathetic neurons. Although PI3-K has been shown to exert antiapoptotic effects in many paradigms, its role in the survival of sympathetic neurons is controversial. The most thoroughly examined neurotrophic factor in this paradigm is NGF. Some authors have reported that blockade of PI 3-K function by different means prevents NGF-mediated survival, ${ }^{3,4}$ whereas others have shown the opposite. ${ }^{5,6}$ The reason for these 
discrepancies is unclear, but it is probably related to both the culture conditions and methods for assessing survival. For example, evaluation of survival relying solely on metabolic assays such as MTT reduction could be misleading since the inhibition of $\mathrm{PI} 3-\mathrm{K}$ reduces the cell size and metabolic activity of these cells (our data ${ }^{6}$ ). Likewise, the use of exceedingly high doses of LY294002, well above those needed to inhibit PI $3-\mathrm{K}$ completely, might cause cellular toxicity or affect other targets than $\mathrm{PI} 3-\mathrm{K}$ itself. Finally, blockade of PI 3-K does not trigger the apoptotic molecular events that take place in NGF-deprived SCG neurons such as Bax translocation to the mitochondria or release of cytochrome $c$ to the cytosol, ${ }^{14}$ further indicating that inhibition of PI 3-K does not mimic the absence of trophic support completely. ${ }^{6}$

Control of cell growth by the PI 3-K/Akt pathway. Knockdown of PDK1, although not affecting cell survival, caused a marked reduction in cell size. Likewise, lack of Ret tyrosine 981, which resulted in an almost complete blockade of Akt phosphorylation, caused a reduction in cell size without affecting survival. Interestingly, mice expressing a hypomorphic mutation for PDK1 are viable and are fertile but have reduced body mass ultimately caused by a decrease in cell size but not in cell number. ${ }^{21}$ Moreover, fibroblasts from these animals undergo apoptosis at the same rate than those from wild-type animals.

We hypothesize that the control of cell size by $\mathrm{PI} 3-\mathrm{K}$ is linked to the activation of mTOR, a kinase, which plays a well-known role in both nutrient sensing and stimulation of anabolism and cell growth. The connection between mTOR and the $\mathrm{PI}$-3-K/Akt has been recently unveiled in the case of the insulin/IGF system by finding that Akt phosphorylates and inactivates the TSC1/TSC2 complex, an inhibitor of mTOR activity (reviewed in Martin and $\mathrm{Hall}^{22}$ ). Thus, the inhibition of $\mathrm{PI} 3-\mathrm{K}$ would result in repression of $\mathrm{mTOR}$ signaling, thereby reducing or stopping GDNF-mediated cell growth.

B-Raf as a key mediator of survival. Our data indicate that B-Raf is necessary for GDNF- and NGF-mediated survival in sympathetic neurons, independently of MEK. This is consistent with data from Wiese et al., ${ }^{23}$ who showed that targeted deletion of B-Raf prevented neurotrophin-mediated survival of embryonic motor and sensory neurons. In that work, the authors also show that lack of B-Raf causes a decrease in expression of IAPs, especially, XIAP. These observations are in agreement with those reported by Kato and colleagues, ${ }^{24}$ who demonstrated that IAPs are essential for GDNF-mediated survival of embryonic motor neurons. Accordingly, we also observed a decrease in XIAP levels concomitant with silencing of B-Raf in our system (Supplementary Figure 4). However, sympathetic neurons from $\mathrm{XIAP}^{-1-}$ mice survive normally in the presence of NGF, ${ }^{25}$ indicating that loss of XIAP expression by itself is not sufficient to preclude NGF-mediated survival of these neurons (see below). A recent report suggests that B-Raf is not necessary for the survival of sensory neurons but instead regulates axon growth in vivo. ${ }^{26}$ We do not know whether these differences are cell specific or on the contrary are due to functional redundancy between family members, or perhaps to incomplete excision of Raf at the onset of programmed cell death of DRG neurons.

Finally, it is worth noting that the central role of B-Raf as an effector of Ret signaling appears to be conserved outside the nervous system, as the RET-RAS-BRAF pathway has been identified as one of the major genetic alterations found in thyroid carcinomas, being its activation responsible for the proliferation and invasive phenotype of these cells. ${ }^{27}$

How do IKKs regulate neuronal survival?. One of the major findings of this paper is that IKKs are targets of B-Raf in sympathetic neurons, and that IKK activity is necessary for NGF and GDNF-mediated survival of these neurons. Although the role of IKKs in neuronal survival has not been addressed thoroughly, results obtained in other systems suggest a plethora of potential mechanisms by which IKKs could block apoptosis. First, antiapoptotic genes such as Bcl-2 family members A1/Bfl-1, Mcl- 1 and $\mathrm{Bcl}-\mathrm{XL}$, or IAPs such as XIAP are found among transcriptional targets of NF$\kappa B$. ${ }^{28}$ Second, IKKs can block the JNK pathway through the activation of $\mathrm{NF}-\kappa \mathrm{B}$. It is well established that the activation of the JNK pathway is necessary for trophic factor withdrawalinduced death of sympathetic neurons. ${ }^{29-32}$ Blockade of the JNK pathway can be accomplished directly by inducing the expression of antagonists of the pathway such as Gadd $45 \beta$ (which blocks the activity of MKK7). ${ }^{33,34}$ It can also be blocked indirectly by inducing the expression of antioxidants such as ferritin heavy chain, ${ }^{35}$ that counteract the production of reactive oxygen species concomitant to some types of cell death, including that occurring in sympathetic neurons after NGF withdrawal. ${ }^{36,37}$ Third, IKKs may exert their protective effects independently of $\mathrm{I} \kappa \mathrm{B} \alpha$ degradation and NF- $\kappa \mathrm{B}$ activation. Thus, it has been shown that $\operatorname{IKK} \beta$ contributes to tumor development by directly phosphorylating and inducing ubiquitin-dependent degradation of the transcription factor FOXO3A. ${ }^{38}$ Interestingly, it has been shown that $\mathrm{Bim}$ is under the transcriptional control of $\mathrm{FOXO}_{3} \mathrm{~A}^{39}$ (although Bim levels can be regulated through other transcriptional and post-transcritpional mechanisms), and that Bim deletion attenuates trophic factor withdrawalinduced death of sympathetic neurons ${ }^{39}$ The contribution of all these potential mechanisms to blockade of sympathetic neuronal cell death by IKKs is currently being investigated.

\section{Materials and Methods}

Antibodies and reagents. Antibodies to Ret9 (C-19G), Ret51(C-20G), A-Raf (C-20G) and B-Raf (F-7) were from Santa Cruz Biotechnology (Santa Cruz, CA). Antibodies to phospho-Akt (Ser473), dually phosphorylated ERK1/2 (Thr202/ Tyr204) and phospho-IKK $\alpha$ (Ser180)/IKK $\beta$ (Ser181) were from Cell Signaling (Beverly, MA). Anti-PDK1 and anti-C-Raf were purchased from BD Biosciences (San Jose, CA). Anti-IKK $\alpha$ and IKK $\beta$ antibodies were from Calbiochem (Darmstadt, Germany), and anti-Bax was from Upstate (Lake Placid, NY). The BIM and XIAP antibodies were obtained from Stressgen (Victoria BC, Canada), and the anti- $\alpha$ tubulin was from Sigma (St. Louis, MO). Anti-PUMA was from ProSci Inc. (Poway, CA). Finally, the antibody against the extracellular domain of Ret has been described previously. ${ }^{17}$ LY294002, PD98059 and U0126 were from Calbiochem. All other reagents were from Sigma.

Cell culture and assessment of neuronal survival. Mouse sympathetic neurons from the superior cervical ganglion of postnatal day 0-1 pups were dissected and cultured essentially as described. ${ }^{40}$ Briefly, ganglia were sequentially digested in collagenase and trypsin (Worthington Lakewood, NJ), 
dissociated by trituration and plated on rat tail collagen-coated dishes in the medium containing $50 \mathrm{ng} / \mathrm{ml}$ NGF (Alomone labs, Jerusalem, Israel), 10\% fetal bovine serum (Invitrogen, Carlsbad, CA) and anti-mitotics for 5 days (AM0 medium). Subsequently, cells were washed three times with media and switched to media containing either anti-NGF, $50 \mathrm{ng} / \mathrm{ml}$ NGF (Alomone) or anti-NGF plus $50 \mathrm{ng} / \mathrm{ml}$ GDNF (Alomone) and $100 \mathrm{ng} / \mathrm{ml}$ Fc-GFRa1 (R \& D Systems, Minneapolis, MN). For survival experiments, one-tenth to one-fifth of a ganglion was plated in 24-well dishes. Neuronal survival was assessed by counting neurons of designated fields before and after treatments at the indicated time points. Typically, around 200-300 neurons per field were counted in triplicate wells. Results were expressed as a percentage of the initially counted cells. Experiments were repeated at least three times, the data was pooled and expressed as mean \pm S.D. For the measurement of soma diameter, pictures were analyzed with the AnalySIS software package (Soft Imaging System GmbH, Germany).

Immunoprecipitation and western blot. For western blot, cells were plated at higher density (typically 1-2 ganglia per well in 24-well or 12-well plates, respectively) and kept in NGF-containing media for 5-7 days. Then cells were washed three times with $\mathrm{AMO}$ and deprived overnight in media containing no NGF. Neurons were stimulated with $50 \mathrm{ng} / \mathrm{ml}$ GDNF plus Fc-GFR $\alpha 1$ or $50 \mathrm{ng} / \mathrm{ml}$ NGF for $10 \mathrm{~min}$. We added GFR $\alpha 1$ to match the culture conditions in survival experiments, even though its presence did not alter the signaling pattern elicited by GDNF (data not shown). Cells were lysed in NP-40 containing buffer ( $150 \mathrm{mM} \mathrm{NaCl}, 50 \mathrm{mM}$ Tris pH 8, 1 mM EDTA, $1 \mathrm{mM}$ EGTA) freshly supplemented with a cocktail of protease inhibitors (Roche Applied Science), $1 \mathrm{mM}$ sodium orthovanadate, $10 \mathrm{mM}$ sodium fluoride and $50 \mathrm{mM} \beta$-glycerophosphate. Alternatively, cells were directly lysed in Laemmli's buffer. Proteins were resolved in SDS-PAGE, transferred to PVDF membranes (Millipore) and blocked in TBST containing 5\% BSA. Primary antibodies were incubated overnight at $4{ }^{\circ} \mathrm{C}$, followed by peroxidase-conjugated secondary antibodies. Immunodetection was performed using ECL-Advance (Amersham, GE Healthcare). X-ray films were scanned with an EPSON Perfection 3200 PHOTO apparatus and acquired with Adobe Photoshop. Densitometric analysis was performed using the Quantity One software (Bio-Rad, Hercules, CA). For immunoprecipitation, NP-40 lysates were incubated with the indicated primary antibodies plus sepharose-bound protein $A$ and/or protein $G$ (Sigma). Immunocomplexes were washed with buffer and boiled in Laemmli's buffer.

Lentiviral delivery of short-hairpin RNAs (shRNAs). Lentiviral-based vectors for RNA interference-mediated gene silencing (FSVsi) consisted on a U6 promoter for expression of short-hairpin RNAs and the venus variant of YFP under the control of an SV40 promoter for monitoring transduction efficiency. Lentiviral particles were produced in $293 \mathrm{~T}$ cells cotransfected by the calcium phosphate method with the above plasmid plus plasmids coding for the envelope and the packaging systems (VSV-G and $\Delta 8.9$, respectively). The day after transfection, 293T cells were switched to AM0 containing no antimitotics and left for 2-3 days. Supernatants were then harvested, filtered through a $0.45 \mu \mathrm{m}$ filter, supplemented with NGF and antimitotics and directly applied to sympathetic neurons. Typically, cells were infected overnight the day after or 2 days after dissection. In experiments aimed to assess the efficacy of gene knockdown by immunoblot, cells were typically kept for 5 days in NGF followed by 2 more days in GDNF, or alternatively 7 days in NGF. When gene silencing was deleterious for the cells, the pan-caspase inhibitor BAF $(50 \mu \mathrm{M})$ was added to the media 2-3 days before lysis. For overexpression of B-Raf, the human CDNA of B-Raf containing a V600E substitution was cloned in a lentiviral expression vector (FCMV), which contains the promoter of human cytomegalovirus. When sequential infections were needed, cells were infected overnight with the first set of viruses, allowed to recover the day after and infected the following night with the second set of viruses. After this second infection, neurons were kept in NGF for 3 more days before proceeding with the different experimental conditions. Viruses expected to promote beneficial effects on survival (i.e., V600E B-Raf and Bax shRNA) were infected first, whereas viruses expected to have deleterious effects were infected afterwards.

Sequences of shRNAs. The following sequences were used for generation of ShRNAs:

PDK1: 5'-TGGTGAGGTCCCAAACTGA-3', PDK1 control: $5^{\prime}$-GGGAATTTCC TAAGGACGC-3', A1: 5'-CCTATGGTGTTGTGCTCTAT-3', A2: 5'-TGCGTTGACA TGAGTACCAA-3'; B1: 5'-GCTACCTTATTCAAACATCAA-3', B2: 5'-GCTTACGA GAAATACACTGAA-3'; C-Raf, C1: 5'-CCTATGGTGTTGTGCTCTAT-3', C2: 5'-TGCGTTGACATGAGTACCAA-3'; Raf Control: $5^{\prime}$-GTCCGGTTCGTTTAGAG
TCTT-3'; IKK $\alpha: 5^{\prime}$-CAGGCTCTTTCAGGGACAT-3'; IKK $\beta: 5^{\prime}$-GCTGCACATTT GAATCTGTAT-3'; IKK control: 5'-GCTCTCTTGAAGGTTGATGTA-3'; Bax 5'-GC AGCTGACATGTTTGCTGAT-3', Bax control 5'-ACTGCCTTGGACTGTGTCTTT-3'.

Acknowledgements. We thank Jason Gustin and Mao Yang for help with lentiviral constructs and also thank Martí Aldea, Carme Gallego and Malú G Tansey for critical reading of the manuscript. This work was supported by grants from Ministerio de Educación y Ciencia (BFU2004-03632 and BFU2007-67619) to ME, NIH Grants AG13730 and NS39358 to JM, AG13729 to EMJ and HD047396-01 to $\mathrm{SJ}$, and funding from Suport als Grups de Recerca (Generalitat de Catalunya) to ME and JXC ME holds a contract from the 'Ramón y Cajal' program. EJR is recipient of a predoctoral fellowship from Ministerio de Educación y Ciencia. XD holds a contract from Fondo de Investigaciones Sanitarias.

1. Airaksinen MS, Saarma M. The GDNF family: signalling, biological functions and therapeutic value. Nat Rev Neurosci 2002; 3: 383-394

2. Airaksinen MS, Titievsky A, Saarma M. GDNF family neurotrophic factor signaling: four masters, one servant? Mol Cell Neurosci 1999; 13: 313-325.

3. Crowder RJ, Freeman RS. Phosphatidylinositol 3-kinase and Akt protein kinase are necessary and sufficient for the survival of nerve growth factor-dependent sympathetic neurons. J Neurosci 1998; 18: 2933-2943.

4. Mazzoni IE, Said FA, Aloyz R, Miller FD, Kaplan D. Ras regulates sympathetic neuron survival by suppressing the p53-mediated cell death pathway. J Neurosci 1999; 19 : 9716-9727.

5. Philpott KL, McCarthy MJ, Klippel A, Rubin LL. Activated phosphatidylinositol 3-kinase and Akt kinase promote survival of superior cervical neurons. J Cell Biol 1997; 139: 809-815.

6. Tsui-Pierchala BA, Putcha GV, Johnson Jr EM. Phosphatidylinositol 3-kinase is required for the trophic, but not the survival-promoting, actions of NGF on sympathetic neurons. J Neurosci 2000; 20: 7228-7237.

7. Jain S, Encinas M, Johnson Jr EM, Milbrandt J. Critical and distinct roles for key RET tyrosine docking sites in renal development. Genes Dev 2006; 20: 321-333.

8. Mora A, Komander D, van Aalten DM, Alessi DR. PDK1, the master regulator of AGC kinase signal transduction. Semin Cell Dev Biol 2004; 15: 161-170.

9. Putcha GV, Harris CA, Moulder KL, Easton RM, Thompson CB, Johnson Jr EM. Intrinsic and extrinsic pathway signaling during neuronal apoptosis: lessons from the analysis of mutant mice. J Cell Biol 2002; 157: 441-453.

10. Wellbrock C, Karasarides M, Marais R. The RAF proteins take centre stage. Nat Rev Mol Cell Biol 2004; 5: 875-885

11. Galabova-Kovacs G, Kolbus A, Matzen D, Meissl K, Piazzolla D, Rubiolo C et al. ERK and beyond: insights from B-Raf and Raf-1 conditional knockouts. Cell Cycle 2006; 5 1514-1518

12. Maggirwar SB, Sarmiere PD, Dewhurst S, Freeman RS. Nerve growth factor-dependent activation of NF-kappaB contributes to survival of sympathetic neurons. J Neurosci 1998; 18: $10356-10365$

13. Hamanoue M, Middleton G, Wyatt S, Jaffray E, Hay RT, Davies AM. p75-mediated NFkappaB activation enhances the survival response of developing sensory neurons to nerve growth factor. Mol Cell Neurosci 1999; 14: 28-40.

14. Putcha GV, Johnson Jr EM. Men are but worms: neuronal cell death in $C$ elegans and vertebrates. Cell Death Differ 2004; 11: 38-48.

15. Melillo RM, Santoro M, Ong SH, Billaud M, Fusco A, Hadari YR et al. Docking protein FRS2 links the protein tyrosine kinase RET and its oncogenic forms with the mitogen-activated protein kinase signaling cascade. Mol Cell Biol 2001; 21: 4177-4187.

16. Besset V, Scott RP, Ibanez CF. Signaling complexes and protein-protein interactions involved in the activation of the Ras and phosphatidylinositol 3-kinase pathways by the c-Ret receptor tyrosine kinase. J Biol Chem 2000; 275: 39159-39166.

17. Encinas M, Crowder RJ, Milbrandt Jr J, Johnson EM. Tyrosine 981, a novel ret autophosphorylation site, binds c-Src to mediate neuronal survival. J Biol Chem 2004; 279 18262-18269.

18. Crowder RJ, Enomoto H, Yang M, Johnson Jr EM, Milbrandt J. Dok-6, a Novel p62 Dok family member, promotes Ret-mediated neurite outgrowth. J Biol Chem 2004; 279 42072-42081.

19. Jiang T, Qiu Y. Interaction between Src and a C-terminal proline-rich motif of Akt is required for Akt activation. J Biol Chem 2003; 278: 15789-15793.

20. Lu Y, Yu Q, Liu JH, Zhang J, Wang H, Koul D et al. Src family protein-tyrosine kinases alter the function of PTEN to regulate phosphatidylinositol 3-kinase/AKT cascades. J Biol Chem 2003; 278: 40057-40066.

21. Lawlor MA, Mora A, Ashby PR, Williams MR, Murray-Tait V, Malone $L$ et al. Essential role of PDK1 in regulating cell size and development in mice. EMBO J 2002; 21: 3728-3738.

22. Martin DE, Hall MN. The expanding TOR signaling network. Curr Opin Cell Biol 2005; 17 158-166.

23. Wiese S, Pei G, Karch C, Troppmair J, Holtmann B, Rapp UR et al. Specific function of B-Raf in mediating survival of embryonic motoneurons and sensory neurons. Nat Neurosci 2001; 4: 137-142. 
24. Perrelet $D$, Ferri $A$, Liston $P$, Muzzin $P$, Korneluk RG, Kato AC. IAPs are essential for GDNF-mediated neuroprotective effects in injured motor neurons in vivo. Nat Cell Biol 2002; 4: 175-179.

25. Potts PR, Singh S, Knezek M, Thompson CB, Deshmukh M. Critical function of endogenous XIAP in regulating caspase activation during sympathetic neuronal apoptosis. J Cell Biol 2003; 163: 789-799.

26. Zhong J, Li X, McNamee C, Chen AP, Baccarini M, Snider WD. Raf kinase signaling functions in sensory neuron differentiation and axon growth in vivo. Nat Neurosci 2007; 10 598-607.

27. Melillo RM, Castellone MD, Guarino V, De Falco V, Cirafici AM, Salvatore G et al. The RET/ PTC-RAS-BRAF linear signaling cascade mediates the motile and mitogenic phenotype of thyroid cancer cells. J Clin Invest 2005; 115: 1068-1081.

28. Kucharczak J, Simmons MJ, Fan Y, Gelinas C. To be, or not to be: NF-kappaB is the answer-role of Rel/NF-kappaB in the regulation of apoptosis. Oncogene 2003; 22 : 8961-8982.

29. Ham J, Babij C, Whitfield J, Pfarr CM, Lallemand D, Yaniv M et al. A c-Jun dominant negative mutant protects sympathetic neurons against programmed cell death. Neuron 1995; 14: 927-939.

30. Eilers A, Whitfield J, Babij C, Rubin LL, Ham J. Role of the Jun kinase pathway in the regulation of c-Jun expression and apoptosis in sympathetic neurons. J Neurosci 1998; 18 1713-1724.

31. Mota M, Reeder M, Chernoff J, Bazenet CE. Evidence for a role of mixed lineage kinases in neuronal apoptosis. J Neurosci 2001; 21: 4949-4957.

32. Xu Z, Kukekov NV, Greene LA. POSH acts as a scaffold for a multiprotein complex that mediates JNK activation in apoptosis. EMBO J 2003; 22: 252-261.
33. De Smaele E, Zazzeroni F, Papa S, Nguyen DU, Jin R, Jones $\mathrm{J}$ et al. Induction of gadd45beta by NF-kappaB downregulates pro-apoptotic JNK signalling. Nature 2001; 414: 308-313.

34. Papa S, Zazzeroni F, Bubici C, Jayawardena S, Alvarez K, Matsuda S et al. Gadd45 beta mediates the NF-kappa B suppression of JNK signalling by targeting MKK7/JNKK2. Nat Cell Biol 2004; 6: 146-153.

35. Pham CG, Bubici C, Zazzeroni F, Papa S, Jones J, Alvarez K et al. Ferritin heavy chain upregulation by NF-kappaB inhibits TNF alpha-induced apoptosis by suppressing reactive oxygen species. Cell 2004; 119: 529-542.

36. Greenlund LJ, Deckwerth Jr TL, Johnson EM. Superoxide dismutase delays neuronal apoptosis: a role for reactive oxygen species in programmed neuronal death. Neuron 1995; 14: $303-315$

37. Jordan J, Ghadge GD, Prehn JH, Toth PT, Roos RP, Miller RJ. Expression of human copper/zinc-superoxide dismutase inhibits the death of rat sympathetic neurons caused by withdrawal of nerve growth factor. Mol Pharmacol 1995; 47: $1095-1100$

38. Hu MC, Lee DF, Xia W, Golfman LS, Ou-Yang F, Yang JY et al. IkappaB kinase promotes tumorigenesis through inhibition of forkhead FOXO3a. Cell. 2004; 117: 225-237.

39. Gilley J, Coffer PJ, Ham J. FOXO transcription factors directly activate Bim gene expression and promote apoptosis in sympathetic neurons. J Cell Biol 2003; 162: 613-622.

40. Deckwerth TL, Johnson Jr EM. Temporal analysis of events associated with programmed cell death (apoptosis) of sympathetic neurons deprived of nerve growth factor. J Cell Biol 1993; 123: 1207-1222.

Supplementary Information accompanies the paper on Cell Death and Differentiation website (http://www.nature.com/cdd) 